\title{
Espacios transgresores: El escenario sacrificial indígena en la historiografía novohispana del siglo XVI
}

Artículo

Afiliación: Princeton University, Nueva Jersey, Estados Unidos de América

E-mail: ncervant@princeton.edu

Recibido: 17 de diciembre del 2018

Aceptado: 27 de mayo del 2019

\section{Nadia Cervantes Pérez}

Doctora en literatura hispánica con especialidad en estudios coloniales por la Universidad de Wisconsin-Madison. Actualmente es docente del Departamento de Español y Portugués de la Universidad de Princeton.

\section{Nadia Cervantes Pérez}

\section{Resumen}

Uno de los aspectos más notables de la historiografía colonial novohispana son los discursos en torno a las prácticas sacrificiales indígenas. Estos rituales dispararon la imaginación de los narradores europeos y se utilizaron para darle forma a sus argumentos en cuanto a la evangelización, conquista y colonización del Nuevo Mundo. Si por un lado se consideraba al espacio americano como un paraíso perdido, es verdad también que los lugares sagrados del mundo indígena fueron respresentados como un espacio infernal de transgresión e idolatría.

En este trabajo amplío la dicotomía infierno-paraíso explicando las diversas maneras en que se construyen los espacios rituales del mundo mesoamericano en los textos coloniales del siglo XVI. En concreto, analizo la manera en que tanto europeos como indígenas presentan tres espacios rituales paradigmáticos en la historiografía novohispana temprana: La isla de los sacrificios, los espacios rituales de Tlaxcala y el Templo Mayor de Tenochtitlan. Argumento que si bien la construcción textual del espacio ritual indígena en la Historia General de Oviedo constituye el espacio transgresor por excelencia, en historias de aspecto evangelizador, como la de Motolinía, se presenta una ambivalencia entre la cultura occidental y la religión nahua a través de oposiciones y paralelismos. Finalmente, explico que la representación de los espacios rituales por parte del cronista indígena Hernando Alvarado Tezozomoc contrasta significativamente con las crónicas europeas al proponer al escenario ritual sacrificial como el locus de la identidad y memoria mexica.

Palabras Clave: espacio; historiografía; México; ritual; sacrificio.

Transgressive spaces: The indigenous sacrificial scenario in the "novohispana" historiography of the 16th century

\section{Abstract}

One notable aspect of Mexico's colonial historiography is its discursive richness in regards to Indigenous sacrificial rites. These rituals enthused the European imagination and were used to articulate a variety of arguments concerning the evangelization, conquest, and colonization of the New World. If, on one hand, Europeans considered the New World as a lost paradise; on the other, Indigenous sacred space was represented in numerous texts as an infernal space of transgression and idolatry.

This article expands on the paradise-hell dichotomy by explaining the various ways in which individuals envisioned ritualistic spaces of the Mesoamerican world during the 16th century. Specifically, I analyze how European and Indigenous individuals articulate three paradigmatic sacred places: the Island of Sacrifices, the ceremonial spaces in Tlaxcala, and the Templo Mayor of Tenochtitlan. While the representation of Indigenous ritual space in Oviedo's Historia General is shaped as a transgressive space, I argue that texts with an evangelizing aim, like Motolinía's account, present an ambivalence vis-à-vis Western culture as they point to oppositions as well as parallels in relation to Nahua religion. Finally, I explain that the textual representation of sacred spaces by the Indigenous chronicler, Hernando Alvarado Tezozomoc, significantly differs from the European accounts, given that sacrificial space is articulated as the locus of Mexican identity and memory.

Keywords: historiography; Mexico; ritual; sacrifice; space. 


\section{Oviedo: la Isla de los Sacrificios}

no de los primeros cronistas que describe el espacio ritual indígena, específicamente los rituales sacrificiales, es Gonzalo Fernández de Oviedo. De acuerdo con Sarah Beckford (2007), su perspectiva histórica estaba influida por las ideas humanistas en torno a la figura del historiador como sabio, aunque también por una preocupación por incorporar la perspectiva y la experiencia vivida del testigo de vista. No obstante, sobre todo en su Historia General (1851/1944), Oviedo propone a la figura del historiador como un peregrino que es testigo de fenómenos y eventos maravillosos, pero que además inquiere y reflexiona sobre ellos. En ese sentido, la historia cumple con una función claramente didáctica y es el medio por el cual Dios transmite su mensaje. Oviedo afirma en el proemio a la primera parte de la Historia General (1535/1944) que la historia está compuesta de hechos y fenómenos que el mismo Dios, de todo nos enseña, para que más loores le demos, el objetivo del historiador debe ser entonces tratar de descifrar el mensaje divino inscrito en el mundo y la naturaleza.

Gonzalo Fernández de Oviedo sin lugar a dudas fue una figura fundamental en el campo historiográfico colonial. Por un lado, formó parte del círculo de privilegiados por los monarcas españoles Fernando e Isabel la Católica, Carlos V y Felipe II y fue la primera persona a quien se le otorgó el privilegio de ser el cronista oficial de Indias. Varios académicos (de los Ríos, 1851-1855; Pérez de Tudela Bueso, 1959; Ballesteros Gabrois, 1981) mencionan que Oviedo ocupó varios puestos tanto en la corte como en la administración colonial en el Nuevo Mundo tales como: mozo de cámara, escribano general, veedor de fundiciones de oro, teniente de gobernador del Darién y alcaide de la fortaleza de Santo Domingo. Por otro lado, también es cierto que después de haber publicado la primera parte de la Historia General (1535/1944), esa misma élite política que le había dado privilegios le negó el permiso para imprimir el resto de su obra, la cual no fue publicada sino hasta 1851. Esto se debe en parte a que Oviedo, portavoz de la ideología imperialista, y por lo tanto portador de una visión políticamente ortodoxa, adopta una posición heterodoxa en la definición de la actividad historiográfica al proponer una nueva forma de concebir el género.

De acuerdo con Kathleen Myers, Oviedo "was a man between two worlds: he fervently defended the interests of the Spanish monarchy and projected the norms of early modern European culture, and yet he realized that the New World needed a different historical approach" (2007, p. 3). Asimismo, otros críticos (Esteve Barba, 1964; Beckford, 2007) han señalado que la obra de Oviedo se caracteriza por su estilo ecléctico y por el constante cuestionamiento y reflexión en cuanto al método y función del historiador, y esta actitud crítica repercutirá en el lugar simbólico que Oviedo ocupa dentro de la jerarquía cultural del momento. Una de las características más importantes de su obra es que no solo describía minuciosamente las costas y la geografía americana, sino que además estos espacios constituían escenarios ejemplares que ilustraban la lucha del imperio cristiano contra la idolatría. En este escenario, el Imperio español sería el representante de la gloria contra el infierno imperante en el Nuevo Mundo.

En el capítulo XIV del libro XVII de la primera parte de la Historia General y Natural de las Indias, Oviedo narra los eventos relacionados al descubrimiento de la península de Yucatán y zonas limítrofes a cargo del capitán Juan de Grijalva en 1518. En este episodio se describe un viaje de reconocimiento el cual consiste en navegar por el litoral del territorio y obtener información de los indios del lugar. Entre los lugares y personas que encuentran, Grijalva y sus hombres hallan una pequeña isleta a la cual nombran La isla de los sacrificios.

El relato de esta experiencia interrumpe la narración de un viaje de reconocimiento y posesión para introducir un pasaje que presenta, por primera vez en la obra de Oviedo, el enfrentamiento de los españoles ante uno de los rituales indígenas más transgresores de la ideología cristiana. En ese sentido, La isla de los sacrificios es un pasaje fundacional de las historias de la conquista de México, el cual se describe como un lugar distópico y como la oposición al paraíso perdido del discurso colombino. Así pues, este pasaje muestra la manera en que el espacio americano ritual se convierte en la historiografía colonial en un lugar paradigmático y predecible de ritos sangrientos y anti-humanos. El propósito de Oviedo al utilizar este escenario será principalmente justificar su visión providencialista de la conquista. 
El pasaje comienza con información espaciotemporal precisa, propia de un discurso naútico-militar: "Viernes, once días de junio de mill e quinientos e diez é ocho años, salió el armada del río de Grijalva, con sus cuatro carabelas, e prosiguió la misma costa la vía del Ponente, e toda la tierra parescía pòblada e llena de edeficios y de gente cerca de la costa de la mar" (Oviedo, 1535/1944, p. 282). Sin embargo, el tono de la narración cambia inmediatamente en el momento en el que el capitán Juan de Grijalva y sus hombres ponen pie en este lugar hasta ese momento ignoto. No es irrelevante el hecho de que el espacio narrado sea una zona completamente cercada por el mar, pues este aislamiento físico también es un cerco metafórico en el que se crea un escenario de incertidumbre y misterio, lo cual contrasta con el tono y la precisión espaciotemporal de los párrafos anteriores.

Oviedo describe el camino que siguen los exploradores una vez que están en tierra, un recorrido entre arboledas en el que de pronto se divisan edificios de piedras antiguos "a manera de adarves ruinados por el tiempo, y derribados en partes" (1535/1944, p. 284). Es decir, que este es un espacio intermedio entre el espacio natural y el espacio de la civilización humana. El escenario descrito remite al lector a un mundo antiguo del que sólo quedan vestigios, a un espacio abandonado y solitario, pero al mismo tiempo rico en significado debido a la acción del hombre.

Posteriormente, el narrador focaliza la atención al centro de la isleta en donde se ubica una edificación, los españoles suben por sus escaleras y encuentran una escultura que "quería parescer león" (1535/1944, p. 284) junto a la cual encuentran una pileta de piedra ensangrentada. La imagen de la sangre fresca apunta entonces a una acción reciente y contrasta con las ruinas descritas anteriormente, pues en este punto de la narración, presente y pasado convergen en un mismo espacio. En seguida, el narrador dirige la atención del lector hacia un ídolo de piedra de cara a la pileta ensangrentada y al avanzar la vista finalmente el narrador nos pone frente a un espectáculo de horror de cabezas ensartadas en palos, así como de huesos, cuerpos lacerados y descompuestos. Oviedo nos informa que en este momento los españoles "espantados", "sospecharon lo que podía ser" (1535/1944, p. 284). Aquí, la idea del sacrificio sólo ha quedado sugerida, aunque la violencia ritual es explícita.

Los indios que aparecen hacia el final de la escena finalmente confirman la sospecha de los españoles. Aunque nunca son plenamente identificados, son ellos quienes les explican a los españoles que los cadáveres son personas que han sido degolladas y a las cuales se les extraía el corazón con navajas de pedernal para posteriormente ser quemados y ofrecidos al ídolo de piedra que previamente habían visto. Después de que el narrador explica que algunas partes del cuerpo de estos hombres eran comidas, finalmente los indios terminan su relato diciendo que estos indios muertos pertenecían a otro grupo con el cual los sacrificadores estaban en guerra. Oviedo concluye:

E así les paresció a nuestros españoles que ello debía ser, e que sacrificaban allí algunos indios de aquella tierra o provincia, y por esto el capitán general mandó que se llamase isla de los Sacrificios y bahía de Sacrificios, allí donde los navíos estaban surtos entre la isleta e la Tierra Firme. (1535/1944, p. 285)

El final del pasaje confirma que el sacrificio humano es la característica identificadora de este espacio recién descubierto, lo cual sentará un precedente en futuros relatos, mapas e ilustraciones sobre la conquista de México. Esto se observará, por ejemplo, en el mapa que Cortés le enviará a Carlos V en el cual se representa un cuerpo sin cabeza en el centro de Tenochtitlan, o en las ilustraciones del impresor y grabador flamenco Theodor De Bry (1528-1598), quien en el libro noveno de los Grandes Viajes (15901634/1992) presenta el único grabado sobre México con una escena sacrificial en lo alto de un templo rodeado de un tzompantli mexica.

Finalmente, el espacio sacrificial de la isla no ofrece certezas ni aclara la naturaleza del otro. Lo que sí hace es ofrecer unas pistas que justifican y legitiman las acciones de conquista por parte de los europeos. El espacio se descifra desde el locus ideológico europeo, lo cual difiere del significado de quienes habitan el espacio, es decir, el espacio sacrificial solo es legible desde el lente de la ideología imperialista occidental. Por lo tanto, en la representación del espacio y del acto de nombrarlo como Isla de los Sacrificios, Oviedo le da sentido a la expedición española dentro de su visión imperialista y providencialista de la historia. Para Oviedo, la eliminación de los ritos de 
los indígenas y la conversión de éstos a la fe católica le da legitimidad a la conquista del Nuevo Mundo, y al mismo tiempo, al ser el testimonio escrito de estos hechos, la Historia General pretende ser una prueba de la acción divina en la historia universal.

\section{Motolínia: escenarios rituales en Tlaxcala}

Las convicciones e influencias milenarias fueron aspectos clave en los textos de Fray Toribio de Benavente, Motolinía (Baudot, 2001; Maravall, 1949; Phelan, 1970; West, 1989). Desde este lente franciscano del milenarismo con propósito evangelizador, Motolinía es uno de los primeros que aborda en profundidad el problema de la conversión de la población indígena y los sacrificios humanos. Este rito tiene una importancia fundamental en sus textos, pues lo presenta ante el lector con viveza y teatralidad para articular una narrativa en la cual la orden franciscana lucha contra el demonio. De esta manera, la descripción y el comentario que hace Motolinía sobre los sacrificios humanos aseguraba que el poder metropolitano estuviera siempre alerta y en constante temor por una vuelta atrás en el proceso de colonización, religiosa y políticamente hablando.

La descripción del espacio ritual de Motolinía se articula en base a una concepción integradora de las prácticas religiosas precolombinas con la teología cristiana, es decir que, a diferencia de la narrativa de Oviedo, el espacio ritual indígena se construye como la otra cara del espacio ritual cristiano. Motolinía poseía una visión universalista de la historia y, en ese sentido, consideraba que la historia indígena tenía su origen en la historia cristiana. Como resultado, la descripción de los elementos formales y teológicos de las prácticas indígenas sirven para articular una narrativa de un proceso de conversión natural, efectivo y pacífico.

Por ejemplo, en la Historia de los Indios (c.1536/2000), Motolinía describe los ritos antiguos de los indígenas de Tlaxcala y posteriormente el escenario de las celebraciones cristianas del Corpus Christi que los sustituyeron, enumerando uno a uno los elementos equivalentes de ambos eventos: los templos, las esculturas de los dioses, los objetos, el decorado, etc. Tal como lo señala Patricia Ybarra (2009), la celebración de la fiesta de Corpus Christi en la Historia de los Indios, sirve para mostrar un puente natural entre el pasado idólatra de rituales sacrificiales y un presente de prácticas devocionales de orden cristiano.

En la descripción de los rituales indígenas y cristianos, opera un principio de sustitución en el cual el sacrificio humano se presenta como el elemento más transgresor y el punto de mayor divergencia entre las religiones cristiana e indígena. En primer lugar, Motolinía caracteriza a los rituales sacrificiales como un escenario infernal, el cual busca provocar la emoción en el espectador. Para ello, Motolinía crea un ambiente grotesco y horrífico a partir de imágenes visuales que empatan los elementos religiosos de la cultura indígena con la del infierno:

Tenían asimismo unas casas o templos del demonio, redondas, unas grandes y otras menores, según eran los pueblos; la boca hecha como de infierno y en ella pintada la boca de una temerosa sierpe con terribles colmillos y dientes, y en algunas de éstas los colmillos eran de bulto, que verlo y entrar dentro ponía gran temor y grima; en especial el infierno que estaba en México, que parecía traslado del verdadero infierno (Motolinía, 2000, p. 30)

Asimismo, las imágenes zoomórficas de los dioses aztecas son presentados con cualidades demoniacas. Todo ello tiene como consecuencia que la religión indígena sea considerada como un plagio demoniaco y por lo tanto como una imagen distorsionada de los ritos y fiestas cristianos. En ese sentido, el escenario representado constituye un paradigma de inversión y parodia del cristianismo. Sin embargo, a la vez que se establece esta distinción, se establece también un paralelismo entre el ritual sacrificial indígena y las festividades instauradas por los franciscanos en el Tlaxcala del siglo $\mathrm{XVI}$, tal como lo indica el concepto de Teonanacatl (carne de los dioses), el cual tiene su paralelo en el concepto del Corpus Christi. Finalmente, Motolinía retóricamente establece la relación entre ambas religiones utilizando los términos y conceptos del cristianismo para aplicarlos a los rituales sacrificiales indígenas como lo es el rito de la comunión o el acto de bendecir. 
El ritual cristiano de la comunión, por ejemplo, tiene su paralelo en el ritual a Tezcatlipoca en la que la carne del sacrificado pasa por un proceso similar al de la transubstanciación cristiana para luego ser consumida por los sacerdotes aztecas, de la misma manera en la que la eucaristía se transforma en el cuerpo de Jesucristo y es consumida por el sacerdote antes de ser ofrecida a los demás participantes en la ceremonia. Esto implica que los conceptos y mecanismos del sacrificio cristiano se transfieren al performance del ritual azteca, y al igual que el ritual de la eucaristía, el sacrificio humano es un acto de conmemoración y de expiación. En suma, lo que es a la vez un evento diferenciador entre dos culturas, encuentra también su punto de unión en el sacrificio. Por ello, no es de sorprender que el proceso de conversión comienza con este rito. En su primer tratado, Motolinía explica a detalle las principales festividades indígenas, haciendo énfasis en la celebración de rituales sacrificiales en los templos para pasar entonces a relatar la manera en que los indios celebraban las festividades cristianas después de la llegada de los misioneros. El paralelismo entre ambas descripciones es evidente. Motolinía describe en el capítulo $X$ del primer tratado una de las fiestas principales de los indígenas, a la que Motolinía llama "su pascua". El franciscano describe:

Antes del día de la fiesta, cuatro o cinco días, ataviaban y aderezaban los templos, y encalábanlos y limpiábanlos; y el tercero día antes de la fiesta, los ministros pintábanse todos, unos de negro, otros de colorado, otros de blanco, verde, azul, amarillo; y así pintados, a las espaldas de la casa o templo principal bailaban un día entero. Luego ataviaban la estatua de aquel su demonio, la cual era de tres estados de altura, cosa muy disforme y espantosa. (2000, p. 58)

Como lo ha explicado Viviana DíazBalsera(2003), los templos nahuas son evidentemente escenarios de horror e idolatría, pero también se representan como un espacio sagrado, el cual los indígenas limpiaban y adornaban tal y como se trataría el espacio sagrado cristiano. Así pues, el espacio ritual implica contraste y continuidad al mismo tiempo. Lo anterior se observa también en los cuerpos pintados de colores brillantes de los indígenas, los cuales contrastan con las vestimentas blancas de los indios principales en la celebración de la Pascua cristiana: "Ios Indios señores y principales, ataviados y vestidos de sus camisas blancas y mantas, labradas con plumajes, y con pidas de rosas en las manos, bailan y dicen cantares en su lengua" (Motolinía, 2000, p. 69). Más aún, el vestido blanco de los señores y principales contrasta también con el vestido "espantoso" hecho de la piel de los desollados con el que los señores y principales se ataviaban durante la celebración de los dioses indígenas:

De aquellos que sacrificaban desollaban algunos, en unas partes dos o tres, en otras cuatro o cinco, en otras diez, y en México hasta doce o quince y vestían aquellos cueros, que por las espaldas y encima de los hombros dejaban abiertos, y vestido lo más justo que podían, como quien viste jubón y calzas, bailaban con aquel cruel y espantoso vestido... para este día guardaban alguno de los presos en la guerra que fuese señor o persona principal, y a aquel desollaban para vestir el cuero de él el gran señor Motecuzoma, el cual con aquel cuero vestido bailaba con mucha gravedad, pensando que hacia gran servicio al demonio que aquel día honraban. (Motolinía, 2000, p. 41)

En estos pasajes, el elemento diferenciador entre las vestimentas sacerdotales es el uso de la violencia, sin embargo, Motolinía establece ahí mismo, en la diferencia más radical, una continuidad ritual. Así, a la vez que se muestra una oposición, se muestra una confluencia en la estructura ceremonial y por lo tanto la conversión constituye un acto de transferencia de formas y no tanto de significados. Otros aspectos espaciales de las ceremonias nahuas y cristianas como el suelo del escenario ritual llaman la atención:

Y el oficial de esta maldad daba con el corazón encima del umbral del altar de parte de afuera, y allí dejaba hecha una mancha de sangre; y caído el corazón se estaba un poco bullendo en la tierra, y luego poníanle en una escudilla delante del altar... y luego tomaban el cuerpo y echábanlo por las gradas abajo a rodar; y llegado abajo, si era de los presos en la guerra, el que lo prendió con sus amigos y parientes llevábanlo, y aparejaban aquella carne humana con otras comidas. (Motolinía, 2000, p. 40)

Todo el camino que tiene de andar la procesión tienen enramado de una parte y de otra, aunque haya de ir un tiro o dos de ballesta, y el suelo cubierto de espadaña y de juncia y de hojas de árboles y rosas, de muchas maneras, y a trechos puestos sus altares muy bien aderezados. (Motolinía, 2000, p. 70) 
En la primera cita se describe la fiesta del Fuego Nuevo, mientras que en la segunda se describe la procesión durante las fiestas de la pascua con la imagen del suelo cubierto de plantas y rosas. Motolinía subraya la mancha sangrienta que deja el corazón tanto en el umbral del altar como en la tierra, lo cual se contrapone al suelo lleno de flores durante la celebración cristiana. De este modo, Motolinía describe cada elemento formal de las ceremonias del pasado y del presente como disímiles pero paralelas.

A través del espacio ceremonial, ya sean los templos nahuas o el espacio de las procesiones cristianas, Motolinía subraya tanto la diferencia radical entre los rituales indígenas y cristianos como su coincidencia o equivalencia. En esta narrativa, el espacio del ritual sacrificial funciona como un espacio liminal en el que los opuestos convergen. Como lo mencioné anteriormente, la historia de Motolinía tiene el objetivo de mostrar un proceso de conversión pacífico. Esta conversión se da a partir de la sustitución ritual, y una vez que todos los elementos del espacio ritual indígena han sido transformados, la conversión se considera completa. La Historia de los Indios se articula pues como un espectáculo del proceso de conversión en el que el lector es testigo de una transformación pacífica y natural del escenario ritual.

\section{Tezozómoc: el Templo Mayor en la crónica mexicana}

Los rituales sacrificiales mexicas en la época prehispánica eran eventos públicos que se caracterizaban por su complejidad y dramatismo. La estética narrativa de Tezozómoc, descendiente de la nobleza mexica, se distingue de otros cronistas en la representación performática de los rituales en el Templo Mayor de Tenochtitlán y en la exaltación de los valores mexicas exhibidos a través de sus ceremonias. Su Crónica mexicana (1598/2001), narra la historia del pueblo mexica-tenochca desde su llegada a Anáhuac hasta el comienzo de la conquista española con la llegada de Hernán Cortés a Tlaxcala. En dicha crónica, el aspecto de la cultura indígena que causa más horror en el europeo es articulado desde un locus de enunciación Otro y sirve como el fundamento de la reconstrucción del pasado indígena.

Una de las características fundamentales del ritual es el aspecto comunicativo de los elementos no verbales del performance. Tezozómoc no explica el contenido cosmológico o ideológico del ritual, sino que se avoca a describir su estructura, su secuencia y sus elementos formales. Esto se observa, por ejemplo, en la descripción de las actividades preparatorias de Moctezuma I para la celebración del tlacaxipehualiztli o sacrificio gladiatorio. Durante la época prehispánica, millones de personas acudían de todos los rincones de Anáhuac para ser testigos de este evento el cual celebraba por varios días las victorias militares de los mexicas (Bueno Bravo, 2009). Asimismo, las víctimas eran cautivos de guerra, las cuales eran inmoladas en honor a Huitzilopochtli y otras deidades, incluido el dios patrono del sacrificio Xipe Tótec o "nuestro señor el desollado" (González González, 2010). De acuerdo con Michel Graulich, esta ceremonia "revivía la masacre mítica de los 400 o innumerables mimixcoa, quienes, según la Leyenda de los Soles, se mostraron negligentes para adorar al sol tras su creación y fueron por ello castigados con la muerte" (en González González, 2010, p. 422).

Además, es posible que esta ceremonia celebrara también la victoria de Hutizilopochtli en Coatepec contra sus 400 hermanos, los Centzonuitznaua, quienes junto a su hermana Coyoloxauhqui intentaron matar a su madre Coatlicue. Esta leyenda, documentada en la Historia general de las cosas de la Nueva España de Fray Bernardino de Sahagún (1569/2000), también conocida como Códice Florentino, explica el nacimiento del dios Huitzilopochtli. Al quedar Coatlicue embarazada de forma mágica, su hija Coyolxauhqui junto con sus hermanos intentan matarla. Huitzilopochtli, quien se encontraba en el vientre de Coatlicue, nace para vencer y matar a sus hermanos. De acuerdo con Kay Almere Read (1998), esta leyenda enfatiza la victoria de un linaje contra otro, así, el linaje de los mexicas se convierte en el pueblo guerrero que terminó con dominar gran parte de Mesoamérica. Asimismo, la representación ritual de este evento mítico junto con la leyenda de los soles demuestra el poderío del pueblo mexica previo a la conquista y es al mismo tiempo una conmemoración de su antiguo dominio sobre lo que en ese momento era ya una colonia española. 
Tezozomoc narra con especial detalle la celebración del tlacaxipehualiztli durante el reinado de Moctezuma I o Moctezuma llhuicamina, el cual corresponde a la cuarta etapa de la construcción del Templo Mayor. Primero, Tezozómoc cuenta cómo Moctezuma I manda que los prisioneros de pueblos sujetos al imperio construyan el espacio del templo en donde se celebrarían las festividades:

Monteçuma acordó de que, pues era mucha la gente de estas prouinçias de Tuzpa y Cuextlam, que ellos ensalçasen y abentajasen en altura de la casa y templo de Huitzilopochtli y que allí ni más ni menos se començase el sacrificio de Huitzilopochtli con matar allí a los guaxtecas presos; y que éstos tales, después de aber hecho el gran cu muy alto, le hiziesen gradas y en medio se pusiese el taxóm adonde abían de ser muertos los tales esclauos abidos en guerra. (1598/2001, p. 45)

La cita anterior pone de manifiesto la profunda relación entre el sacrificio, la guerra y el espacio sagrado del Templo Mayor. La pirámide de Hutizilopochtli representaba el lugar del nacimiento del dios y de su poderío contra sus enemigos, y como explica Michel Graulich (2010), éste era también el lugar en el que fue enterrado el corazón de Copil, sobrino enemigo de Huitzilopchtli, y donde creció el nopal que sería la señal para fundar ahí Tenochtitlan, la capital mexica. Éste y otros eventos míticos hacían de este espacio "un lugar de poder, de triunfo, de contacto con las deidades de la tierra y del cielo" (Graulich 2010, p. 408). De esta forma, Tezozómoc enfatiza el simbolismo religioso-militar que el templo de Hutizilopchtli tenía, pero también el enorme poder que este dios y su imperio iban adquiriendo.

Aunque Tezozómoc no menciona explícitamente los fundamentos ideológicos en que se basa la construcción del templo, en la descripción del espacio arquitectónico se reflejan los conceptos nahuas del orden del universo puesto que la orientación del espacio sagrado y el posicionamiento de las entradas del templo responde a la cosmología mexica, la cual ordena y divide las regiones del cosmos y señala las cuatro esquinas del universo. Esta orientación del espacio sagrado ha sido estudiada por Mircea Elíade (2001). Para Elíade, el ritual explica el cosmos y el orden del universo y expresa que la arquitectura de los templos de distintas culturas responde a modelos míticos y funcionan como axis mundi. Sin embargo, es importante recalcar que el Templo Mayor de Tenochtitlán estaba compuesto por dos santuarios, el de Hutizilopchtli y el de Tláloc, por lo que el estudio del espacio sagrado de Elíade no explica completamente el modelo mítico nahua. De cualquier modo, es verdad que a partir de la geografía y arquitectura del Templo Mayor se transmite el conocimiento cosmológico implícito en ella. En esta geografía, además de demarcarse los rumbos del universo, se ubica también su centro, la unión de los distintos niveles y direcciones. El templo constituye ese punto de unión, por lo que el ritual sacrificial que ahí se celebra adquiere también su valor simbólico.

Además, es importante notar que el Templo Mayor era el centro ceremonial mexica más importante. Read (1998) ha señalado la relación entre la ancestral ciudad tolteca de Teotihuacan y la capital mexica, Tenochtitlan. De acuerdo con esta académica, los mexicas consideraban a la primera ciudad como antecesora de su propia cultura, de manera que el Templo Mayor fue diseñado en parte tomando como modelo Teotihuacan. Los templos de ambas ciudades estaban configurados en coordinación con la bóveda celeste, específicamente ambos templos estaban orientados hacia el amanecer equinoccial, el cual tenía lugar durante el mes del tlacaxipehualiztli.

Por otro lado, el hecho de que esta ceremonia se celebraba en un escenario tan imponente resalta la dimensión teatral del ritual sacrificial y su propósito de crear una experiencia intensa en el espectador. Tezozómoc describe los eventos del tlacaxipehualiztli como eventos multitudinarios y estéticamente sofisticados que presentaban ante el público una serie de acciones cuidadosamente planeadas. Tezozómoc describe cuidadosamente las actividades en preparación a la celebración, el preludio al sacrificio, a las personas invitadas, el gesto de los sacrificados al dirigirse al templo, la manera en que se sujeta a la víctima, los movimientos y bailes del ritual, la vestimenta de los sacerdotes, la comida que se prepara y los ritos postsacrificiales.

Uno de los aspectos espaciales más importantes es la función que tenían las piedras, altares y artefactos utilizados en los rituales sacrificiales tales como los téchcatl (piedra de sacrificio), el cuauhxicalli (recipiente de madera que recibía el corazón del sacrificado), el teponaztli (tambor de madera) y el tzompantli (estructura en donde se ensartaban las 
cabezas de los sacrificicados). Rocío Cortés (2003) explica que la Crónica mexicana de Tezozómoc (1598/2001) y la Historia de las Indias de Diego Durán (1974) son dos textos que sirvieron como referencia en obras historiográficas importantísimas que describieron el Templo Mayor y sus artefactos en épocas posteriores como las de Boturini Benaducci, Gemelli Carreri, Francisco Javier Clavigero, Mariano Veytia, y Antonio León y Gama. Desde una perspectiva antropológica, Michel Graulich (2010) explica también la función de diferentes objetos utilizados en los rituales sacrificiales basándose en gran parte en las descripciones de Tezozómoc. La Crónica mexicana narra, por ejemplo, cómo Moctezuma l les encomienda a los pueblos de Azcapotzalco y Coyoacán la piedra sacrificial en donde habían de morir las víctimas en las ceremonias durante el mes del tlacaxipehualiztli. Tezozómoc cuenta la conversación entre el máximo sacerdote, Çihuacoatl Tlacaelel, y Moctezuma I al respecto:

Respondió Çihuacoatl Tlacaeleltzin $\langle q u e\rangle<e>$ staua muy bien acordado y que no fuese el taxón de madera sino de piedra rredonda, <en> medio aguxerada para echar los coraçones de los cuerpos que allí muriesen, después de auer gustado la sangre de ellos caliente Huitzilopochtli. Y que esta piedra no la labrasen los guastecas sino los de Azcapuçalco y Cuyuacan, eçelentes albañies, labradas en ella la guerra de sus pueblos quando por nosotros fueron bençidos y muertos y sujetados a este $n<$ uest>ro ymperio mexicano. (1598/2001, p. 145-146)

Esta descripción es la del famoso cuauhxicalli-temalacatl de Moctezuma, una rueda de piedra sobre la cual tendría lugar el sacrificio gladiatorio de los prisioneros de guerra y que serviría también como repositorio de los corazones de los sacrificados.

De acuerdo con Michel Graulich (2016), la piedra tenía una barra que atravesaba el agujero del centro a la cual se ataba al cautivo para que así se enfrentara sucesivamente a cuatro guerreros mexicas vestidos de águilas y jaguares antes de ser sacrificado. Tezozómoc describe la función de la piedra sacrificial durante los actos previos al sacrificio principal o tlahuahuanaliztli (el acto de rayar o señalar a la víctima) de la siguiente manera:

Començaron a cantar y bailar alrededor de la piedra rredonda, frontero del gran ydolo de piedra, untados todos los cuerpos de albayalde (tiçatl) y enplumados y por çima de las cabeças atados los cauellos como trançado, todos con sus pañetes (maxtlatl), y los sacerdotes asentados <en>sillas de hojas de çapotes verdes y todo el suelo sembrado de las mesmas hojas de çapote y alrededor de la piedra <que> llaman amalocoyo. (1598/2001, p. 147)

Como ya lo mencioné, este acto público era presenciado por una multitud, por lo que no es difícil imaginar su carácter de espectáculo. El despliegue de movimientos, sonidos, colores y formas apelan a los sentidos y recrean el escenario del ritual para que así el lector aprecie el espectáculo en una posición de espectador. Así mismo, el canto y el baile marcan el inicio del ritual y con él la transición a un tiempo y un espacio sagrado.

El momento clave de la celebración llegaba con el tlahuahuanaliztli o la danza en la que la víctima lucha contra varios guerreros mexicas, uno a uno, en un combate desigual. Este combate se realiza también sobre la piedra de sacrificio o el cuauhxicallitemalacatl el cual adquiere su dimensión sagrada al servir como lugar de transición entre dos esferas de la realidad. Al respecto, Claude-François Baudez (2010) afirma que el tlahuahanaliztli era un rito de pasaje de la muerte al renacimiento en el que los mexicas se asimilaban a sus adversarios. El momento clave de esta transición entre la esfera terrenal y sagrada, en particular entre la muerte del cautivo y su renacimiento, se da cuando el guerrero mexica lo derriba en la piedra sacrificial y la sangre y corazón del cautivo es ofrecida a Huitzilopochtli.

Tezozómoc explica también que esta piedra fue colocada en lo alto del templo y frente a la estatua de Huitzilopochtli para luego explicar que este espacio ritual puede apreciarse en el presente colonial: "como oy día se bee <en> una esquina de la casa de un bezino hijo de conquistador; y la piedra del sacrifiçio está oy junto a la Iglesia Mayor de la çiudad de Mexico" (1598/2001, p. 146). De esta forma, el espacio narrado no solo nos refiere al pasado del imperio mexica y sus mitos fundacionales, sino que además da cuenta de la transformación y la re-significación que se produce en la época colonial. 
Todo lo anterior pone de manifiesto la complejidad de narrar el pasado indígena y la eficacia de Tezozómoc al transmitir no solo el discurso oral de los antiguos mexicanos sino el performance de su poder, de su ideología y de su historia. El espacio sacrificial mexica, es en este contexto un lugar que puede ser leído por un conocedor de la cultura nahua. El espacio revela así los significados religiosos más valiosos de la civilización mexica. En la época en que Tezozómoc escribe su crónica, esta descripción es uno de los pocos remanentes de la pompa de las prácticas devocionales colectivas prehispánicas, pero sobre todo es uno de los pocos documentos que hacen perdurar la memoria de la élite mexica y de las prácticas religiosas que le daban su razón de ser a su sociedad.

\section{Conclusión}

En conclusión, el espacio ritual-sacrificial fue concebido por los cronistas que relataron los sucesos relativos a la conquista de México desde ideologías muy distintas y con propósitos narrativos únicos. La posición de un cronista oficial como Fernández de Oviedo, de un sacerdote evangelizador como Motolinía o de un historiador mexica constituyen perspectivas éticas y estéticas muy diferentes con respecto al sacrificio y con ellas establecen su posición en el campo historiográfico americano. Asimismo, este análisis puede servir como punto de partida para el estudio de la función poética y política del escenario sacrificial. Desde su representación en códices prehispánicos y en las obras del teatro evangelizador, hasta el uso del escenario sacrificial en la cultura visual del discurso nacionalista post-revolucionario del siglo XX (por ejemplo, en la obra de muralistas como Diego Rivera), la representación del escenario sacrificial en México ha servido siempre como una manera productiva de re-imaginar el pasado e influir en el presente. Es así que el papel de los textos coloniales que describen estos rituales resultan fundamentales en el estudio de la representación simbólica de las prácticas sacrificiales y los usos estéticos e ideológicos de los valores de las culturas indígenas.

\section{Referencias bibliográficas}

Alvarado Tezozómoc, H. (2001). Crónica mexicana. En Díaz Migoyo, Gonzalo yVázquez Chamorro (Eds.). Madrid: Dastin.

Ballesteros, G. (1981). Gonzalo Fernández de Oviedo. Madrid: Fundación Universitaria Española.

Baudez, C. (2010). Sacrificio de 'sí', sacrificio del 'otro'. En Leonardo López Luján y Guilhem

Olivier (Eds.). El sacrificio humano en la tradición religiosa mesoamericana (pp. 431449). Ed. México: INAH.

Baudot, G. (2001). Los precursores franciscanos de Sahagún del siglo XIII al siglo XVI en Asia y América. Estudios de cultura náhuatl, 32, 159-173. Recuperado de https://dialnet.unirioja.es/.

Beckford, S. (2007). Territories of History. Humanism, Rhetoric and the Historical Imagination in the Early Chronicles of Spanish America. University Park, Penn: The Pennsylvania State University Press.

Bueno Bravo, I. (2009). El sacrificio gladiatorio y su vinculación con la guerra en la sociedad mexicana. Gladius, 29, 185-204. Recuperado de http://gladius.revistas. csic.es/.

Cortés, R. (2003). ¿Dónde está Tlaloc? Edificación real y simbólica del imperio en fuentes escritas y materiales. MLN, 18(2), 341-362.

De Bry, T. (1992). América (Grandes Viajes). En Gereon Sievernich (Ed.). Madrid: Ediciones Siruela. 
De los Ríos, A. (1851). Vida y juicio de las obras de Gonzalo Fernández de Oviedo. Introducción. Historia General y Natural de las Indias. Madrid, Real Academia de la Historia.

Díaz Balsera, V. (2003). Erasing the pyramid under the cross: Motolinía's History of the Indians of New Spain and the construction of the Nahua Christian subject. Journal of Spanish Cultural Studies, 4(1), 111-123. DOI: 10.1080/1463620032000058712.

Durán, D. (1974). Historia de las Indias de la Nueva España y Tierra Firme (Vols. 1-2) México: Editorial del Valle de México.

Elíade, M. (2001). El mito del eterno retorno. Buenos Aires: Emecé.

Esteve Barba, F. (1964). Historiografía indiana. Madrid: Gredos.

Fernández de Oviedo y Valdés, G. (1944). Historia general y natural de las Indias, Islas y tierra Firme del Mar Océano (Vols. 1-8). Asunción: Guarania.

González González, C. (2010). El sacrificio humano como generador de prestigio social. Los mexicas y el llamado sacrificio gladiatorio. En Leonardo López Luján y Guilhem Olivier (Eds.). El sacrificio humano en la tradición religiosa mesoamericana (pp. 419-430).. México: INAH.

Graulich, M. (2010). Los lugares, las piedras y los altares de sacrificio. En Leonardo López Luján y Guilhem Olivier (Eds.). El sacrificio humano en la tradición religiosa mesoamericana (pp. 407-417).. México: INAH.

El sacrificio humano entre los aztecas. (2016). México: Fondo de Cultura Económica. Maravall, J. (1949). La utopía político-religiosa de los franciscanos en Nueva España. Estudios Americanos, 2, 199-227.

Motolinía, Fray Toribio de Benavente. (2000). Historia de los indios de la Nueva España. En Joaquín García Icazbalceta (Ed.) Colección de documentos para la historia de México [1858] (pp. 1-249). México: Librería de J.M. Andrade. Recuperado de http://www.cervantesvirtual.com.

Myers, K. (2007). Fernández de Oviedo's Chronicle of America. A New History for a New World. Austin: University of Texas Press.

Phelan, J. (1970). The Millennial Kingdom of the Franciscans in the New World. Berkeley: University of California Press.

Pérez de Tudela y Bueso, J. (1959). Vida y escritos de Gonzalo Fernandez de Oviedo. Historia general y natural de las Indias, Islas y tierra firme del Mar Océano (viiclxix). De Gonzalo Fernández de Oviedo (Vols. 1-5). Madrid: BAE.

Read, K. (1998). Time and Sacrifice in Aztec Cosmos. Bloomington: Indiana University Press. de Sahagún, Fray Bernardino. (2000). Historia general de las cosas de la Nueva España (3 ed., Vols. 1-3). México: Cien de México.

West, D. (1989). Medieval Ideas of Apocalyptic Mission and the Early Franciscans in Mexico. The Americas, 45, 293-313. DOI: 10.2307/1007224.

Ybarra, P. (2009). Performing Conquest. Five Centuries of Theater, History, and Identityin Tlaxcala, Mexico. Ann Arbor: The University of Michigan Press. 